\title{
Effect of Twisted Fin Array in a Triple-Tube Latent Heat Storage System during the Charging Mode
}

\author{
Mohammad Ghalambaz ${ }^{1,2}{ }^{\circledR}$, Jasim M. Mahdi ${ }^{3}\left(\mathbb{D}\right.$, Amirhossein Shafaghat ${ }^{4}$, Amir Hossein Eisapour ${ }^{4}{ }^{\circ}$, \\ Obai Younis $5,6 @$, Pouyan Talebizadeh Sardari $7, *(\mathbb{D}$ and Wahiba Yaïci $8, * \mathbb{1}$
}

1 Metamaterials for Mechanical, Biomechanical and Multiphysical Applications Research Group, Ton Duc Thang University, Ho Chi Minh City 758307, Vietnam; mohammad.ghalambaz@tdtu.edu.vn

2 Faculty of Applied Sciences, Ton Duc Thang University, Ho Chi Minh City 758307, Vietnam

3 Department of Energy Engineering, University of Baghdad, Baghdad 10071, Iraq; jasim@siu.edu

4 Department of Energy and Aerospace Engineering, School of Mechanical Engineering, Shiraz University, Shiraz 7193616548, Iran; amirhosein.shafaghat@gmail.com (A.S.); a.h.eisapour@gmail.com (A.H.E.)

5 Department of Mechanical Engineering, College of Engineering at Wadi Addwaser, Prince Sattam Bin Abdulaziz University, Wadi Addwaser 11991, Saudi Arabia; oubeytaha@hotmail.com

6 Department of Mechanical Engineering, Faculty of Engineering, University of Khartoum, Khartoum 11111, Sudan

7 Faculty of Engineering, The University of Nottingham, Nottingham NG7 2RD, UK

8 CanmetENERGY Research Centre, Natural Resources Canada, 1 Haanel Drive, Ottawa, ON K1A 1M1, Canada

* Correspondence: pouyan.talebizadehsardari@nottingham.ac.uk (P.T.S.); wahiba.yaici@canada.ca (W.Y.); Tel.: +44-115-8376859 (P.T.S.); +1-613-996-3734 (W.Y.)

check for updates

Citation: Ghalambaz, M.; Mahdi, J.M.; Shafaghat, A.; Eisapour, A.H.; Younis, O.; Talebizadeh Sardari, P.; Yaïci, W. Effect of Twisted Fin Array in a Triple-Tube Latent Heat Storage System during the Charging Mode. Sustainability 2021, 13, 2685.

https: / doi.org/10.3390/su13052685

Academic Editors: Reza Sabzehgar and Mehrdad Moallem

Received: 6 February 2021

Accepted: 24 February 2021

Published: 2 March 2021

Publisher's Note: MDPI stays neutral with regard to jurisdictional claims in published maps and institutional affiliations.

Copyright: (C) 2021 by the authors. Licensee MDPI, Basel, Switzerland. This article is an open access article distributed under the terms and conditions of the Creative Commons Attribution (CC BY) license (https:// creativecommons.org/licenses/by/ $4.0 /)$.

\begin{abstract}
This study aims to assess the effect of adding twisted fins in a triple-tube heat exchanger used for latent heat storage compared with using straight fins and no fins. In the proposed heat exchanger, phase change material (PCM) is placed between the middle annulus while hot water is passed in the inner tube and outer annulus in a counter-current direction, as a superior method to melt the PCM and store the thermal energy. The behavior of the system was assessed regarding the liquid fraction and temperature distributions as well as charging time and energy storage rate. The results indicate the advantages of adding twisted fins compared with those of using straight fins. The effect of several twisted fins was also studied to discover its effectiveness on the melting rate. The results demonstrate that deployment of four twisted fins reduced the melting time by $18 \%$ compared with using the same number of straight fins, and 25\% compared with the no-fins case considering a similar PCM mass. Moreover, the melting time for the case of using four straight fins was $8.3 \%$ lower than that compared with the no-fins case. By raising the fins' number from two to four and six, the heat storage rate rose $14.2 \%$ and $25.4 \%$, respectively. This study presents the effects of novel configurations of fins in PCM-based thermal energy storage to deliver innovative products toward commercialization, which can be manufactured with additive manufacturing.
\end{abstract}

Keywords: triple-tube heat exchanger; phase change material; thermal energy storage; latent heat; twisted fin array; heat transfer

\section{Introduction}

The paramount significance of thermal energy storage (TES) in sustainable technologies and the mismatch of the renewable energy supply to the energy load demand have led many experts to devote their research works to the development of TES. A classic example to clarify the advantage of TES is its utilization in solar energy-driven systems. By reducing the temperature fluctuations in the system and storing the excess energy, TES enables the energy supply system to operate at a lower cost [1]. Moreover, this strategy helps the peak-shaving load, resulting in a lower carbon footprint in energy systems [2]. 
Although the application of sensible heat TES is wide and mature, the decisionmakers' attention has been devoted to phase change materials (PCMs) during the last few decades [3]. This is because PCMs can be charged and discharged approximately at an isothermal situation, which is of great thermodynamic importance. Moreover, PCMs possess high energy density, making them suitable to store vast amounts of thermal energy in a small volume [4-6]. Nonetheless, the major limitation of PCMs is the low thermal conductivity [7-10], which has encouraged many researchers to set up innovative ideas to overcome the issue. In this regard, there are various approaches, including using fins, geometry modification, and improvement of the design parameters [11]. These strategies can be adopted on the basis of the application, type of materials used in the system, and the required energy storage rate [12].

There are numerous pieces of research focusing on the application of fins in heat transfer augmentation of latent heat thermal energy storage (LHTES) systems. In an experimental study, Kamkari and Shokouhmand [13] presented the melting process of PCMs in a transparent rectangular enclosure with/without horizontal fins. The results revealed that an increasing number of fins was followed by an increasing overall fin effectiveness and melting enhancement ratio. Yildiz et al. [14] numerically evaluated the impact of two types of fins, including rectangular and tree-like branching fins, in a photovoltaic (PV) module incorporated with PCMs. The results revealed that applying a tree-like branching fin at the same PCM mass was not as constructive as a rectangular fin. Tang et al. [15] studied the melting process in a heat exchanger unit using non-uniform fins. The impact of different types of fin arrangements, angles, and lengths on the thermal performance of the horizontal thermal storage unit was studied. The results showed that by implementing the best configuration, the melting time of the PCM unit and thermal storage unit density were reduced by $83.9 \%$ and increased by $466 \%$, respectively.

The characteristics of the thermal storage unit with fins utilized inside the tubes were proposed by Dai et al. [16]. Various configurations of fins were studied. The obtained results indicated that fin structure can significantly decrease the melting time. Furthermore, the average enhancement ratio of $14.79 \%$ was achieved when employing one long fin instead of two short fins. It is worth mentioning that the charging efficiency was improved by $40 \%$ with the appropriate fin configuration. In a numerical study, Yang et al. [17] studied the effect of different fin pitches and positions in a non-uniform structure to accelerate the charging process in LHTES units. When employing non-uniform fins, the results showed a $62.8 \%$ and $34.4 \%$ decrease in the melting time and average PCM temperature compared to using uniform fins.

Nakhchi and Esfahani [18] investigated the performance of LTHES with various configurations of stepped fins. They used the enthalpy-porosity approach to model the charging process of the storage numerically. The results reflected that all proposed stepped fin configurations perform better than conventional straight fins. In this way, by using downward stepped fins, a $65.5 \%$ enhancement in the melting time of the PCM was obtained. The melting process in a shell and tube LHTES system utilizing various fin array configurations was analyzed in terms of fin height and angle by Mahood et al. [19]. They used RT50 in horizontal thermal energy storage as a PCM. The results indicated that the charging time was decreased by rising fin height. Moreover, reducing the angle between fins enhanced the performance of the thermal energy storage unit. Overall, the fin angle variations and height improved the melting time by $40 \%$ and $50 \%$, respectively.

The optimization of fin design parameters is another strategy to improve the heat transfer rate in the LHTES systems. The optimizations are generally performed on variables such as fin thickness, number, height, and pitch. There are several algorithms that have been applied for optimizations in the literature. To enhance the performance of the heat transfer process for electronic devices cooling, Dammak et al. [20] determined an optimized configuration of a heat fin filled with PCM using a reliability-based design optimization (RBDO). For the best configuration, the results of thermal optimization indicated that the consumed time by the latent heating phase is higher compared to that achieved by the 
base configuration. In a numerical study, the charging process of the triplex-layer PCM in a horizontal heat exchanger was evaluated by $\mathrm{Xu}$ et al. [21]. They employed RT42, RT50, and RT60 as PCMs. A comprehensive storage density capacity (CSDE) parameter was introduced to evaluate the melting performance of the LHTES unit with triplex-layer PCMs. Regarding the introduced criterion, the optimized model offered a $36.2 \%$ increase in CSDE compared to the case in which the uniform radial fin arrangement was implemented. Augspurger et al. [22] developed a strategy to propose an accurate simulation-based optimization model. Firstly, the used a numerical approach to calculate the heat and mass transfer within different designed geometries. Secondly, they utilized pre-screening to identify the independent parameters with the most nonlinear impact on the objective function through the optimization process. Eventually, to receive a multidimensional response surface, a dynamic Kriging-based model was employed. Afterward, the identification of an optimal design was the response surface made using the response surface. The combination of the three approaches led them to obtain an optimal finned thermal energy storage unit.

One of the literature methods to optimize the configuration of LHTES units is the Taguchi optimization algorithm [23-27]. In an experimental investigation, Lin et al. [28] conducted the impact of primary design parameters of the air-based PCM thermal energy storage system using the Taguchi method. Sun et al. [29] experimentally evaluated a platetype LHTES under distinct circumstances to realize the influence of heat transfer fluid (HTF) temperature and velocity, as well as the plate inclination. The charging processes were analyzed by considering the liquid fraction, temperature profiles, and stored energy density. The results of the study showed that at the HTF temperature of $55^{\circ} \mathrm{C}$, the velocity of $5 \mathrm{~m} / \mathrm{s}$, and the plate inclination of $75^{\circ} \mathrm{C}$, the maximum charging rate of $759 \mathrm{~W}$ was obtainable by employing the Taguchi optimization method. Lin and Ma [22] presented an optimization of a building-integrated PCM-based solar photovoltaic thermal (PVT) collector. The signal-tonoise $(\mathrm{S} / \mathrm{N})$ ratio of the coefficient of the thermal performance improvement of the building was considered as an objective function of the study. The optimized system using the Taguchi method showed that the CPTE of the building increased from $45.54 \%$ to $72.22 \%$.

In this paper, three-dimensional numerical simulations are carried out to investigate the effect of the addition of twisted fins in a triple-tube latent heat storage system. Fins are added to the PCM in the middle tube and placed in a staggered configuration. The performance of the innovative configuration of the fins is then compared with the straight fins and no-fins cases. Liquid and temperature contour plots, as well as melting time and melting rate variations, are studied comprehensively to assess the phase change process. Moreover, the effects of twisted fin numbers are investigated. The outcomes of the current research deliver guidelines for the innovative design of latent heat storage systems.

\section{Geometry and Boundary Conditions}

A triple-tube LHS system with twisted fins (Figure 1a) was investigated in this study compared with no-fin and straight fin cases, shown in Figure 1. The system was positioned vertically, and PCM region was located in the middle tube. Hot water with the uniform inlet temperature of $50{ }^{\circ} \mathrm{C}$ and Reynolds number of 1000 passed through the inner and outer tubes using RT35 as the PCM. The adiabatic outer tube was chosen to neglect heat loss from the system to the environment. Pressure outlet was applied for the outlet, and uniform inlet temperature and velocity were employed for the inlet. For the wall surfaces, the no-slip boundary condition was applied. Note that because of the advantages of counter-current flow directions for the working fluid to have a higher melting rate, this method was employed in this study [30]. The inner, middle, and outer diameters of the system were 20, 42, and $64 \mathrm{~mm}$, respectively. The thickness of the inner and middle tubes was considered $2 \mathrm{~mm}$, considering copper for the material of the fins and inner tube. Four fins of straight and twisted configurations were made of copper and were externally and internally attached to the inner tube and the middle tube, respectively, as shown in Figure 1. The fin pitch for the case of twisted fins was $3 \mathrm{~cm}$, and the number of twisted fins was $(2 \leq$ Nfin $\leq 6)$. 


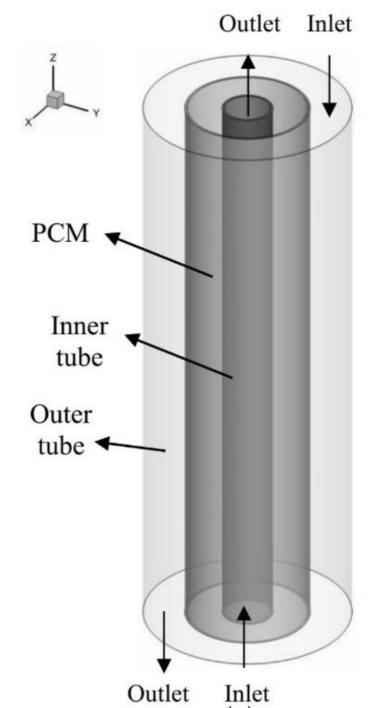

(a)

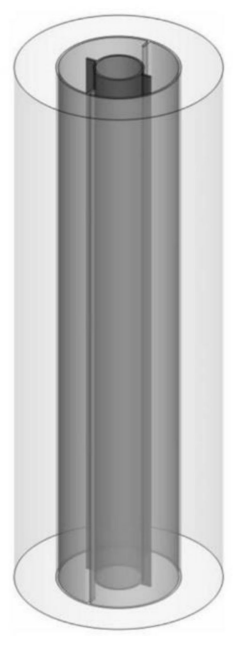

(b)

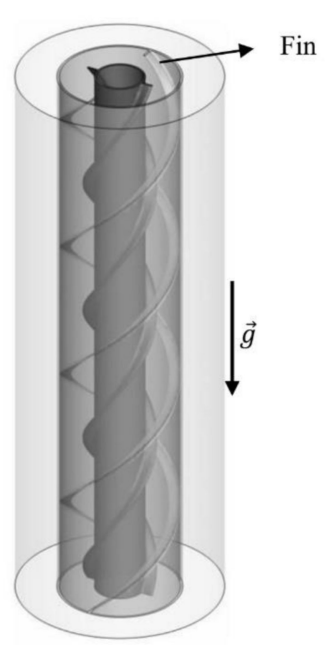

(c)

Figure 1. The schematic of the proposed double-tube heat exchanger with twisted fins using: (a) no fins, (b) straight fins, and (c) twisted fins.

RT35 was employed as the PCM in this study. RT35 is among the organic PCMs, and its melting temperature is suitable for low-temperature building applications. The properties of RT35 are presented in Table 1.

Table 1. Thermo-physical properties of RT35 [31].

\begin{tabular}{cc}
\hline Property & RT35 \\
\hline Specific heat $(\mathrm{kJ} / \mathrm{kgK})$ & 2 \\
Viscosity $(\mathrm{Pas})$ & 0.023 \\
Heat of fusion $(\mathrm{kJ} / \mathrm{kg})$ & 170 \\
Liquidus temperature $\left({ }^{\circ} \mathrm{C}\right)$ & 35 \\
Density $\left(\mathrm{kg} / \mathrm{m}^{3}\right)$ & 815 \\
Thermal conductivity $(\mathrm{W} / \mathrm{mK})$ & 0.2 \\
Solidus temperature $\left({ }^{\circ} \mathrm{C}\right)$ & 29 \\
Thermal expansion coefficient $(1 / \mathrm{K})$ & 0.0006 \\
\hline
\end{tabular}

\section{Mathematical Modeling}

To calculate the phase change process numerically, the enthalpy-porosity approach was employed where, in each cell, the porosity and the liquid fraction were considered equal [32]. The Newtonian free convection flow of melted PCM was generated because of the buoyancy forces, which were transient and placed in the laminar flow regime because of the range of fluid velocity in the domain. The Boussinesq approximation was also employed in the momentum equation because of the small temperature gradient. Thus, the governing equations were derived based on these assumptions and are as follows; considering neglecting Viscous dissipation [33]:

$$
\begin{gathered}
\frac{\partial \rho}{\partial t}+\nabla \rho \vec{V}=0 \\
\rho \frac{\partial \vec{V}}{\partial t}+\rho(\vec{V} \nabla) \vec{V}=-\nabla \mathrm{P}+u\left(\nabla^{2} \vec{V}\right)-A_{m} \frac{(1-\lambda)^{2}}{\lambda^{3}+0.001} \vec{V}-\rho_{r e f} \beta\left(T-T_{r e f}\right) \vec{g} \\
\frac{\rho C_{p} \partial T}{\partial t}+\nabla\left(\rho C_{p} \vec{V} T\right)=-\left[\frac{\partial \rho L_{f}}{\partial t}+\nabla\left(\rho \vec{V} \lambda L_{f}\right)\right]+\nabla(k \nabla \mathrm{T})
\end{gathered}
$$


where $\vec{V}, T, \lambda$, and $P$ are the velocity vector, temperature, liquid volume fraction, and pressure, respectively; while $t$ is time. $T_{\text {ref }}$ and $\rho_{\text {ref }}$ are the reference temperature and density. The third term on the right-hand side of Equation (2) represents the momentum sink for the phase change in the mushy zone [34]. The symbols $L_{f}, \rho, C_{\mathrm{p}}, k, \mu, A_{m}$, and $\beta$ are the latent heat of fusion, density, specific heat capacity, thermal conductivity, dynamic viscosity, mushy, and volume expansion coefficient, respectively.

It is worth mentioning that the volume expansion of the PCM changing from the solidstate to the liquid-state was neglected [35], and the mushy zone constant was considered $10^{-5}$ based on the validation process and literature [32]. To simulate the flow of the water in the inner tube, the governing equations were the same as the above equations, ignoring the additional source of body forces and phase change. The liquid fraction, $\lambda$, is introduced as [36]:

$$
\lambda=\frac{\Delta H}{L_{f}}=\left\{\begin{array}{lll}
0 & \text { if } & T<T_{S} \\
\left(T-T_{S}\right) /\left(T_{L}-T_{S}\right) & \text { if } & T_{S}<T<T_{L} \\
1 & \text { if } & T>T_{L}
\end{array}\right\},
$$

where the subscripts $S$ and $L$ denote the solidus and liquidus states of PCM, and $\Delta H$ is the enthalpy variation during the phase change. A detailed description of the mathematical model can be found in the authors' previous work [32]. The total enthalpy $(H)$ is achieved as:

$$
H=\Delta H+h,
$$

in which,

$$
h=\int_{T_{r e f}}^{T} C_{p} d T+h_{r e f}
$$

The thermal energy storage rate $\dot{Q}$ is introduced as [37]:

$$
\dot{Q}=\frac{Q}{t_{m}}=\frac{m\left(\int_{S} C_{p} d T+L_{f}+\int_{L} C_{p} d T\right)}{t_{m}},
$$

where $t_{m}$ is the melting time and $m$ is the mass of PCM.

\section{Numerical Process}

ANSYS computational fluid dynamic software (FLUENT) was employed to solve the problem using the SIMPLE algorithm for the pressure-velocity coupling scheme. The QUICK scheme was used to discretize the derivatives terms in the momentum and energy equations, while the PRESTO scheme was used for the pressure correction equation. For different equations governed, $10^{-6}$ was used as the convergence criteria. The grid independence analysis was performed prior to the main simulations considering different mesh and time step sizes to determine the results independent from the grid number and the time step size. The results showed that for the case of twisted finned triple-tube with four fins, 2,357,000 cells were enough to have independent results from the number of grids tested, as shown in Figure 2. The size of the time step was also selected equal to $0.2 \mathrm{~s}$. The configuration of the final mesh is shown in Figure 3.

The publication of Mat et al. [38] was used, and the employed geometry was regenerated in this study to verify the accuracy of the present numerical simulation. Mat et al. [38] assessed a fined double-tube LHTES unit using RT58 as the PCM, since the studied geometry was almost similar, based on the concept of the geometry investigated in this paper. They examined the presence of inserted fins connected to both inner and outer tubes in the PCM shell in a staggered configuration using constant wall temperature as the heat source both numerically and experimentally. The results of the validation study are displayed in Figure 4. Excellent agreement is displayed comparing the presented results for both the liquid fraction and average temperature with the numerical and theoretical results of Mat et al. [38]. 


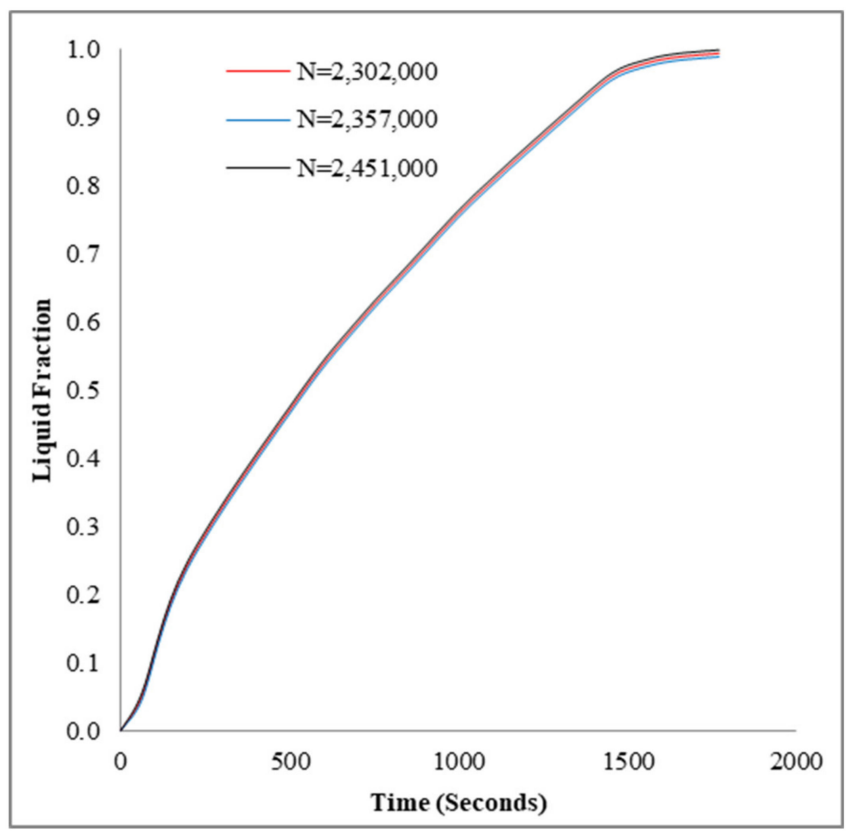

Figure 2. The grid independence analysis.
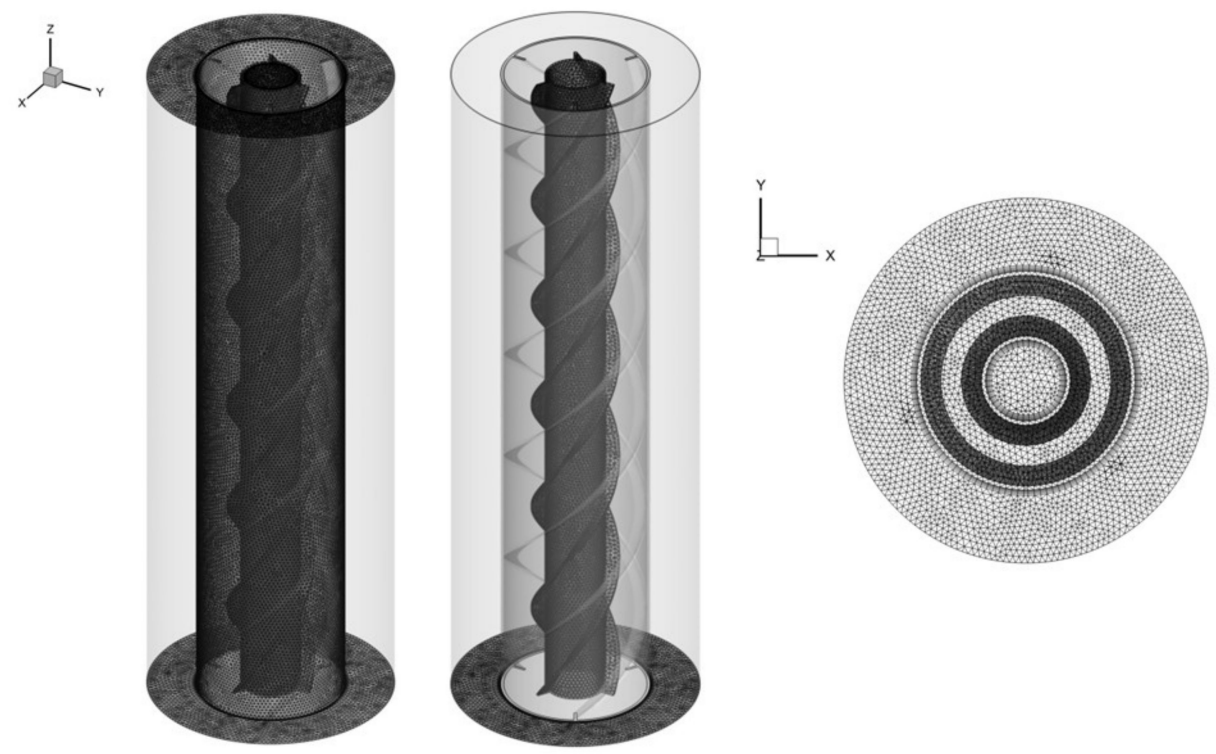

Figure 3. The configuration of the mesh after grid independence analysis.
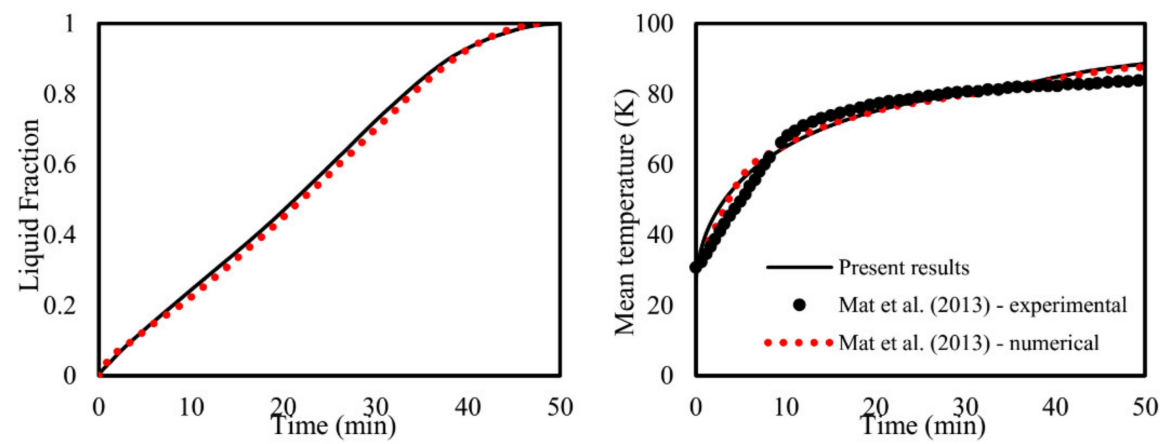

Figure 4. Verification of the present numerical study for both the temperature and liquid-fraction variation compared with Mat et al. [38]. 


\section{Results and Discussion}

A number of simulation studies were carried out to explore the possible enhancement in the melting of paraffin RT35 by employing twisted fins in a vertical triplex-tube TES device. Several simulation cases were considered, including no fins, straight fins, and twisted fins. The number of twisted fins was varied as two, four, and six fins. The total mass of PCM was set at $0.3354 \mathrm{~kg}$ in all cases. The potential of twisted fins as thermal performance enhancers was assessed in terms of liquid-fraction evolution contours, isothermal contour distribution, and temporal liquid-fraction profiles. In each of these cases, the scenario to reach complete melting was assumed to start with solid PCM at an initial temperature $\left(T_{\text {int }}=288 \mathrm{~K}\right)$ which was below the PCM solidus temperature $\left(T_{s}=302 \mathrm{~K}\right)$. The HTF (water) was assumed to be pumped at temperatures above the PCM melting point $\left(T_{H T F}=323 \mathrm{~K}\right)$. This triggered the PCM molecules near the thermally active walls to initiate the melting phase by creating a melting layer adjacent to each solid wall. Over time, these layers steadily expanded in size to invade the whole PCM domain by collecting more heat from the thermally active walls. Simultaneously, the existence of fins, either twisted or straight, served as an additional heat-transfer promoter, as can be seen later in this section.

To compare the impact of including twisted fins on melting in the vertical annular cavity hosting the PCM, the contours of the liquid-fraction evolution (Figure 5) and isotherm distribution (Figure 6) were examined over different times durations (600 s, 1200 s, and $1800 \mathrm{~s}$ ) of melting progress.

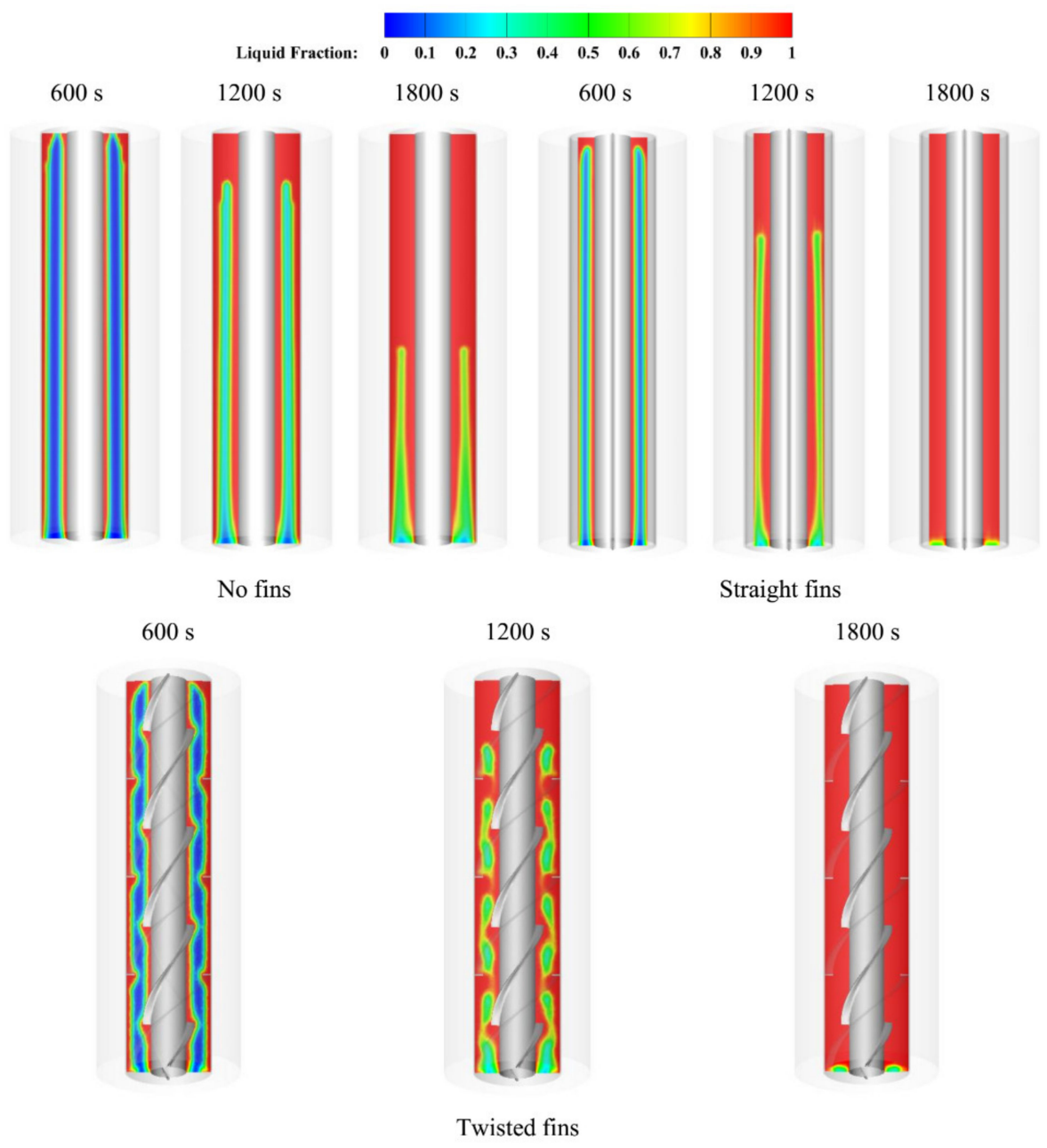

Figure 5. Liquid-fraction evolution contours for different cases of no fins, straight fins, and twisted fins at various time durations. 


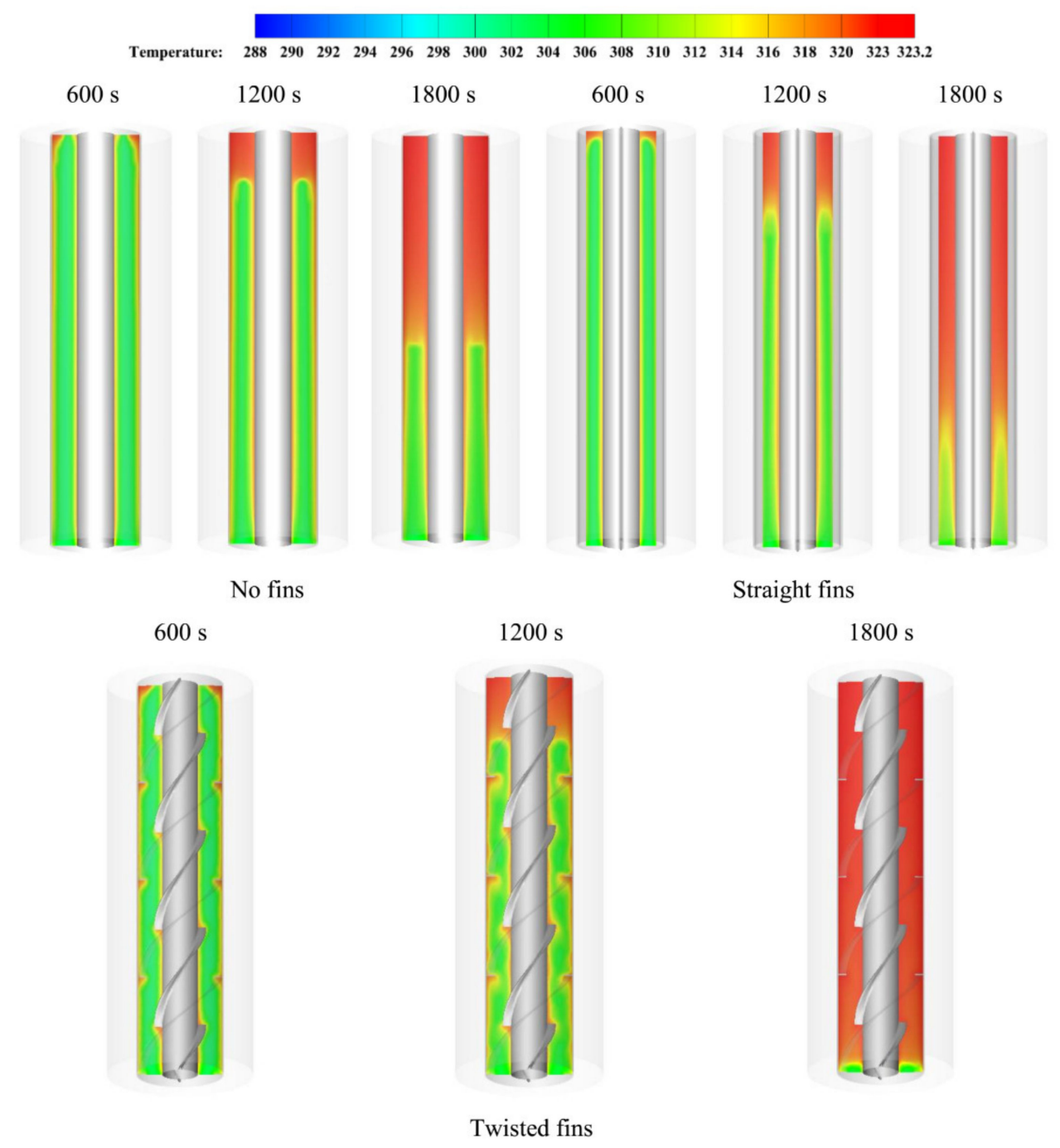

Figure 6. Temperature distribution contours for the different cases of no fins, straight fins, and twisted fins at various time durations.

During the early duration $(t \leq 600 \mathrm{~s})$, the base case of no fins revealed that the melting fronts (represented by light yellow) were almost taking the shape of vertical lines thoroughly parallel to the tube walls. In other cases (with fins), larger melting layers (red zones) close to and around the fins appeared to be greatly encouraged by heat transfer enhancement due to the inclusion of fins, particularly twisted fins, at $t=600 \mathrm{~s}$, as shown in Figure 5. The uniform shape of the melting front in the case of no fins and the case of straight fins indicated that the heat transfer was mainly by conduction and natural convection only had a limited contribution during this period of melting. However, more displacement in the shape of the melting front was visible in the case of the twisted fins compared to other cases during the second duration of $t=1200 \mathrm{~s}$. The hot melted parts of the PCM that originally inhabited the lower half of the cavity continued to travel slightly upward under the buoyancy effect, inducing a stronger convective flow inside the upper half of the cavity than the lower half in all cases. This pattern was similar but more pronounced in the case of twisted fins than in the other cases. This can be seen when comparing the size of the melt layer (red zone) among the different cases considered at $t=1200 \mathrm{~s}$. during the last duration ( $t \geq 1800 \mathrm{~s}$ ), the melt layer rose to the extent of the annulus in the cases with fins, regardless of the configuration (twisted or straight), compared to the base case of no fins. The early completion of melting in the upper portion was attributable to the continuous growth effect of natural convection compared to that of heat conduction. However, the 
leading role of natural convection was more noticeable in the case of twisted fins than straight fins. Such outcomes can be better realized when straight fins and twisted fins are compared at the earlier duration of $t=1200 \mathrm{~s}$.

Figure 6 demonstrates the isotherm distributions for each duration of $600 \mathrm{~s}$ for the three cases reported of no fins, straight fins, and twisted fins. The isotherms displayed a set of condensed lines parallel to the tube walls in all cases at $t=600 \mathrm{~s}$. The explanation is that pure conduction dominates the heat transfer process during this early duration. Therefore, the heat diffusion from the solid walls into the sold PCM is mainly dictated by conduction, and there is no significant effect in the inclusion of fins on the distribution of isotherms. During the subsequent duration ( $t=1200 \mathrm{~s}$ ), the isotherms marginally began to move to a less uniform shape in cases with fins, which indicates a natural convection role within the heat transfer process. This trend in the isotherm distribution was more noticeable in the case of twisted fins than in the case of straight fins. This indicates that twisted fins can boost better natural convection within the liquid PCM. However, the supremacy of conduction over convection remained a persistent characteristic in all cases during the whole melting progress. During the last duration $(t=1800 \mathrm{~s})$, the isotherms appeared more uniform and consistent in color than in earlier melting durations, particularly in the upper half of the cavity, because of the good role of natural convection in the region, which works as another supply of heat transfer to the liquid PCM. Isotherms of high temperatures above $320 \mathrm{~K}$ (the red zones) were the dominant pattern over the entire cavity in the case of twisted fins compared to the case of straight fins. This means that the entire process of melting remained conduction-dominated. The little influencing role of convection was better in twisted fins than in other cases, particularly in the upper parts of the PCM domain.

Figures 7 and 8 compare the liquid-fraction contours and isotherm distributions at various cross-sections of the cases with two, four, and six twisted fins. The top portions of the vertical TES unit showed a tremendous isothermal deformation, representing the dominant convection role in this region. In all studied cases, the bottom region was dominated by conduction, and minor isothermal deformation occurred. In fact, the flow of liquid PCM within the different parts of the PCM domain is by the buoyancy effect, generated as a product of temperature gradients across the domain and gravity. The convective flow of liquid PCM is primarily confined to the upper portion of the domain, under which the buoyant force exceeds the gravitational force. This is why the PCM at the top terminated melting and appeared completely red earlier than that on the bottom, as shown in Figure 7. Raising the number of fins from two to four and six fins further supported the completion of melting at the different upper portions. The melting front appeared to move at a faster rate with increasing fin numbers, since twisted fins enhance heat transport by two aspects. First, their large surface area results in higher heat transfer by conduction across the different parts of PCM, and second, their twisted structure allows for the better role of natural convection.

Figure 9a compares the histories of liquid-fraction evolution during melting for the three cases of no fins, straight fins, and twisted fins. The three TES systems were designed to have the same PCM mass usage $(m=0.3354 \mathrm{~kg})$. Hence, meaningful performance comparisons could be performed. The figure suggests that the twisted fin configuration gave the best potential to enhance melting performance among the three cases studied. The results from Figure 9a indicate that the twisted fins achieved more favorable enhancement to the PCM melting rate than either the base case of no fins or the case of straight fins under the same PCM mass limitation. The time data from the figure indicate that the case of four twisted fins can save time for melting completion, decreasing from $2828 \mathrm{~s}$ to only $2123 \mathrm{~s}$, achieving almost $25 \%$ time-saving results. Also, the data indicate that the inclusion of twisted fins instead of straight fins can reduce the melting time from $2593 \mathrm{~s}$ to $2123 \mathrm{~s}$, so that about $18 \%$ of the total melting time can be saved. Figure $9 \mathrm{~b}$ shows the histories of average PCM temperature variation during melting for the three studied cases of no fins, straight fins, and twisted fins. The figure indicates that the maximum PCM temperature in the case with twisted fins was obtained in a shorter time compared to the 
cases with no fins and straight fins. This means that when the array of twisted fins is used instead of straight fins or the reference case of no fins, the time to reach the maximum melting temperature can be saved considerably. It would be worth indicating here that the present results regarding the decrease of melting time due to the inclusion of fins of different configurations are consistent with earlier studies such as Tang [15], Yang et al. [17], and Mahdi and Nsofor $[39,40]$. This is attributable to the fact that adding fins to the PCM provides a significant way to increase the heat exchange with the heat-transfer fluid, thus enhancing the heat diffusion rate and rapid melting throughout the PCM domain.

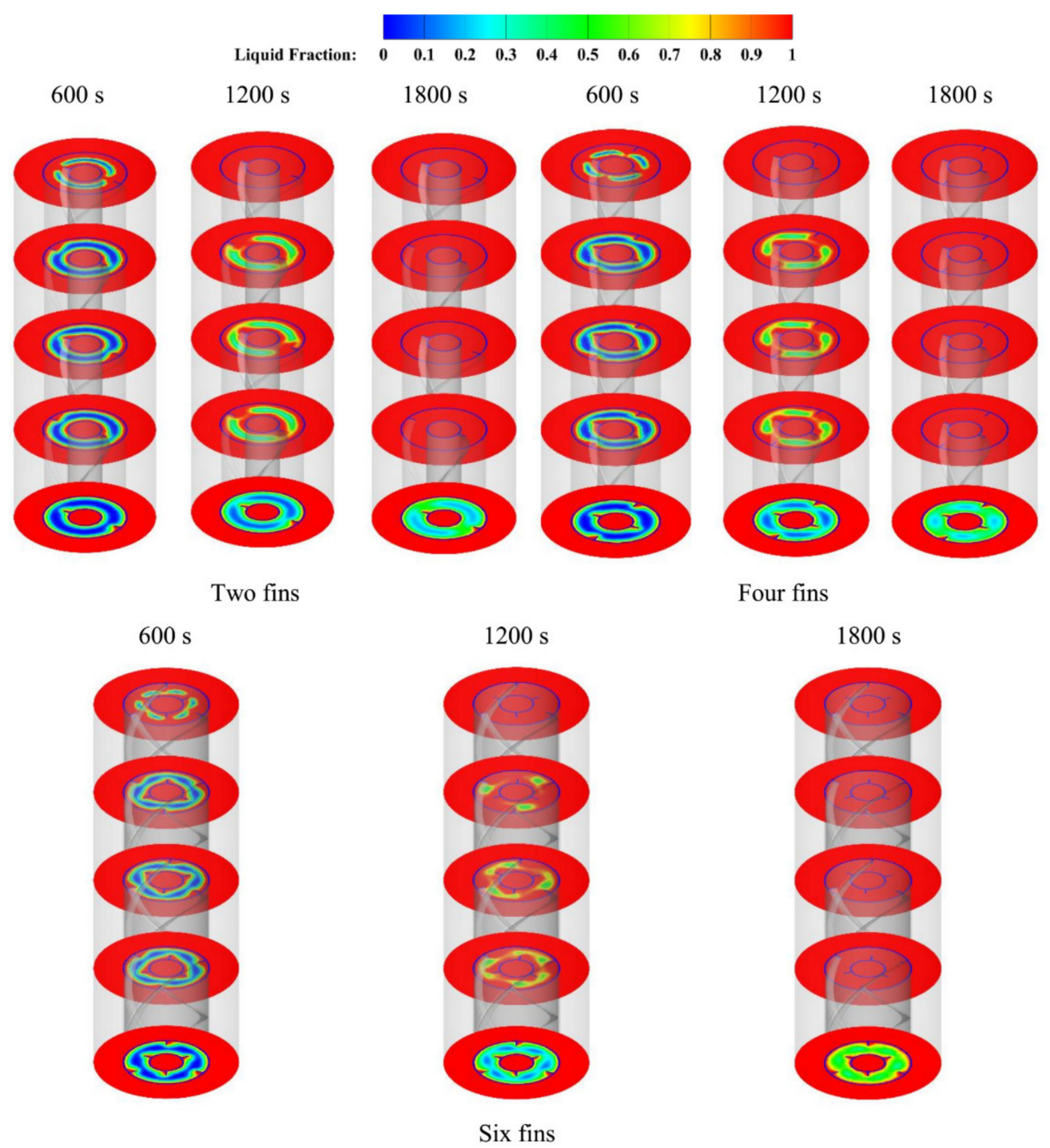

Figure 7. Temporal evolution of liquid-fraction contours at different cross-sections for the cases with different number of fins. 


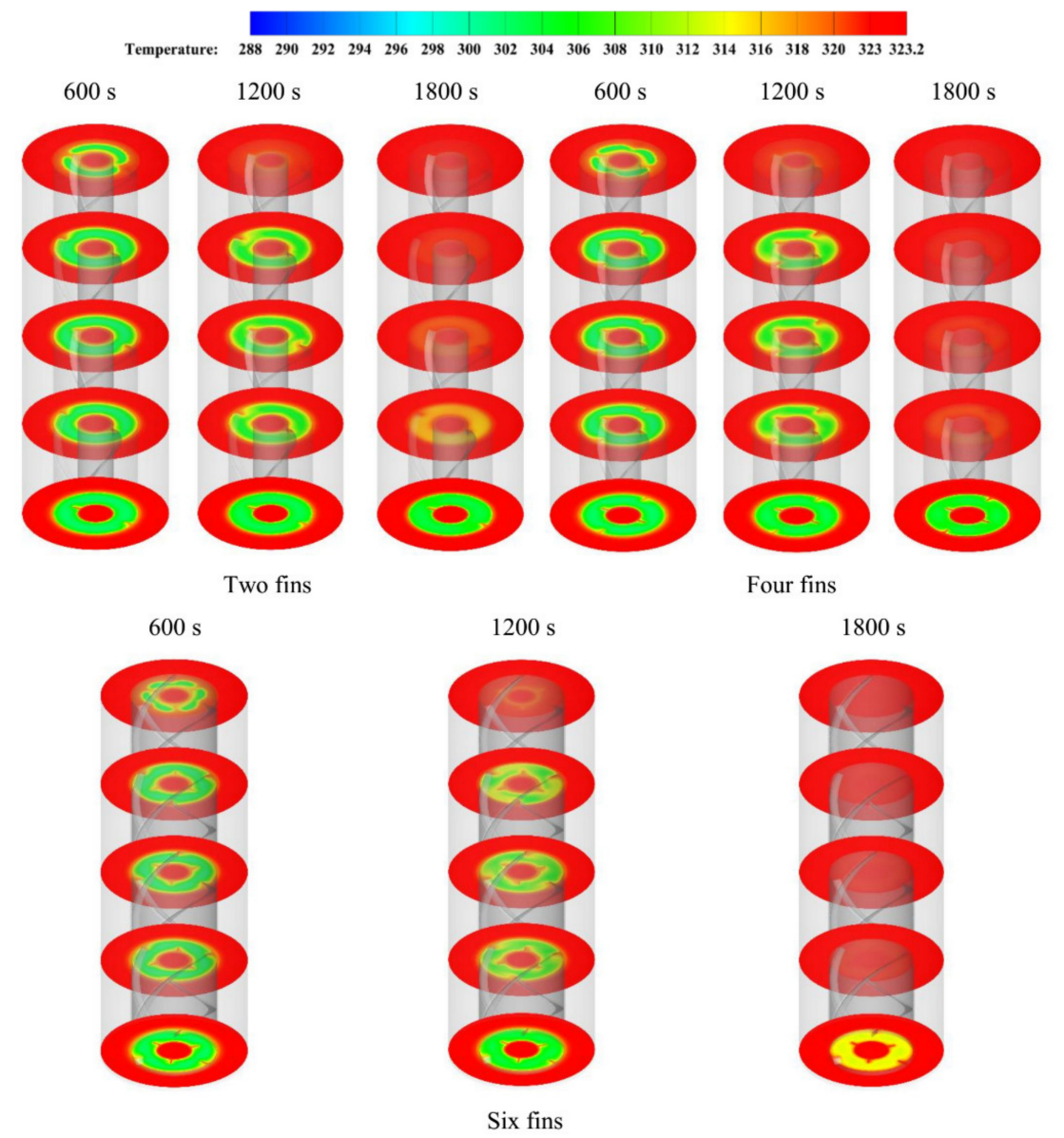

Figure 8. Temporal evolution of temperature distribution contours at different cross-sections for the cases with various number of fins.

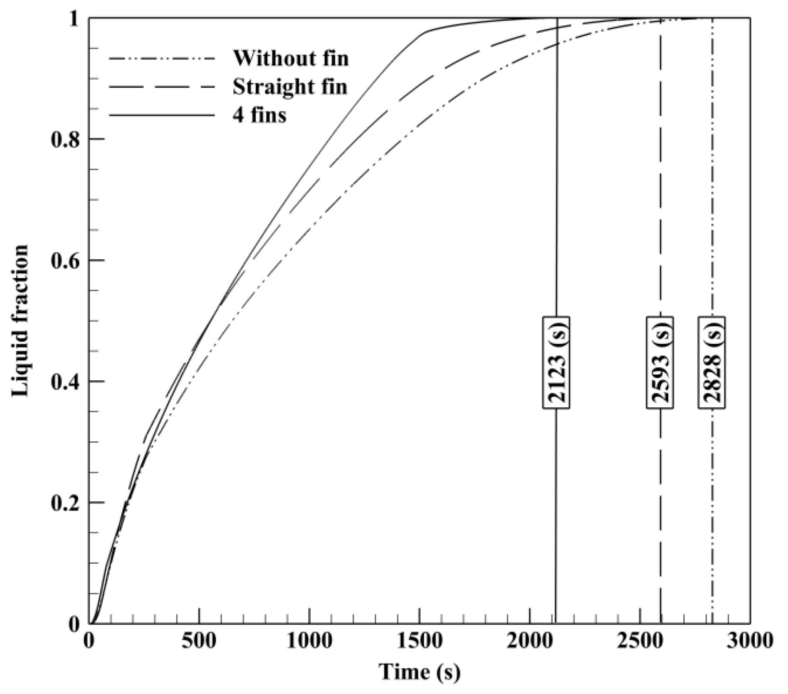

(a)

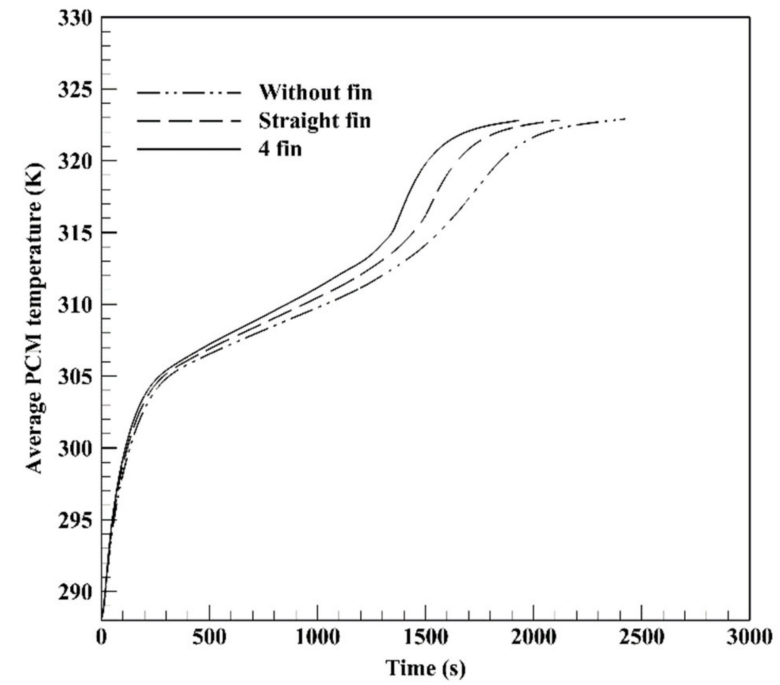

(b)

Figure 9. Characteristics of (a) the phase change material (PCM) liquid-fraction profile and (b) average PCM temperature profile during the melting process for the cases of no fins, straight fins, and twisted fins.

The effects of including fins on heat storage capacity, total melting time, and heat storage rate for all the three cases studied are listed in Table 2. Data from the table demonstrate that a fast heat storage rate with reduced melting time and high storage rate 
was the best when twisted fins were applied compared to the reference cases of straight fins or no fins. The PCM could be charged to store heat at a storage rate of $36.24 \mathrm{~W}$ in the case of twisted fins, and $29.67 \mathrm{~W}$ in the case of straight fins, compared to only $27.19 \mathrm{~W}$ in the base case of no fins. This resulted in almost 33\% and 10\% faster storage of heat due to the inclusion of twisted fins and straight fins, respectively, compared to the reference case of using no fins. Therefore, both twisted fins and straight fins can generate a faster storage rate within the same PCM mass usage, but the highest storage rate was achieved when twisted fins were included.

Table 2. The possible improvement in the heat storage capacity, melting time, and heat storage rate time for the cases of no fins, straight fins, and twisted fins.

\begin{tabular}{ccccc}
\hline Fins & PCM Mass (kg) & $\begin{array}{c}\text { Heat Storage } \\
\text { Capacity (J) }\end{array}$ & $\begin{array}{c}\text { Melting Time } \\
\text { (s) }\end{array}$ & $\begin{array}{c}\text { Heat Storage } \\
\text { Rate (W) }\end{array}$ \\
\hline No fins & 0.3354 & $76,903.13$ & 2828 & 27.19 \\
\hline Straight fins & 0.3354 & $76,953.70$ & 2593 & 29.67 \\
\hline Four twisted fins & 0.3354 & $76,938.91$ & 2123 & 36.24 \\
\hline
\end{tabular}

Figure 10a shows a comparison for the histories of liquid-fraction evolution for the cases of two, four, and six twisted fins. As illustrated in the figure, the case of six twisted fins gave the best enhancement in terms of the total melting time. From the data for the complete melting times, it can be concluded that the trend for achieving faster melting rates depends on the number of twisted fins used, so that the melting rate is faster as the number of fins is higher. The time data indicate that the design with two twisted fins took $2425 \mathrm{~s}$ to finish the melting process while it took only $2123 \mathrm{~s}$ and $1933 \mathrm{~s}$ for the cases of four and six fins, respectively. This means that when the number of twisted fins is doubled from two to four and six fins, the total melting time can be saved by between $12 \%$ and $20 \%$, respectively. Figure 10b shows the histories of average PCM temperature variation during melting for the cases of two, four, and six twisted fins. The average temperature rose to its maximum value in a shorter time in the case of six fins against the cases of four fins and six fins.

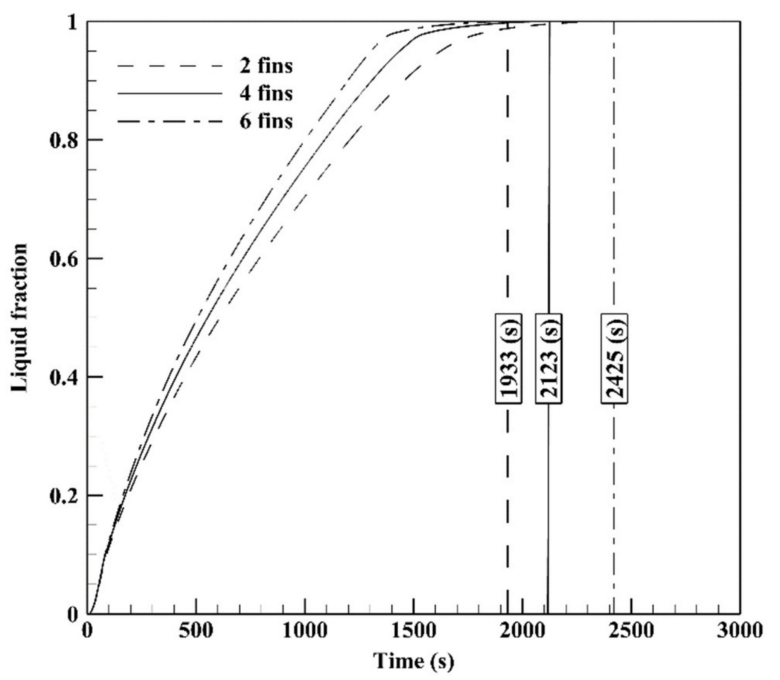

(a)

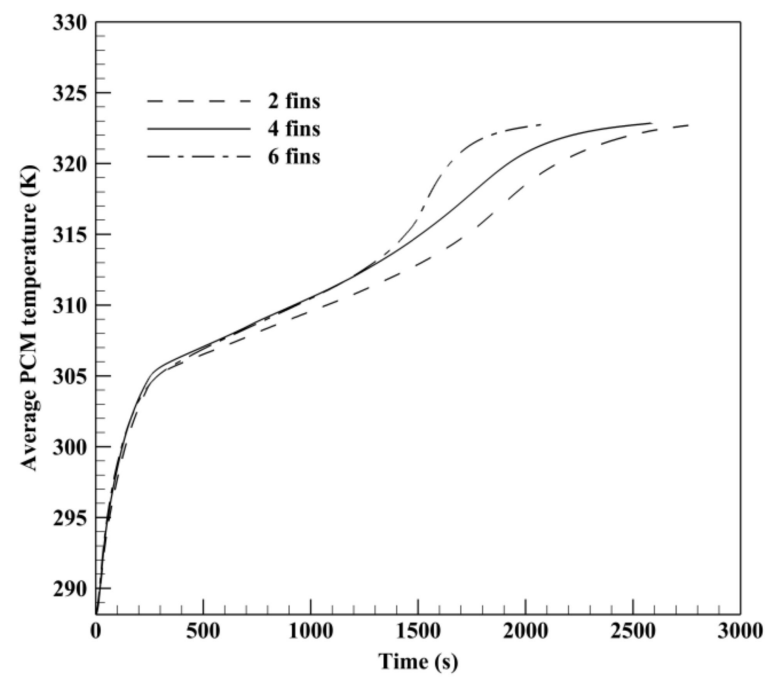

(b)

Figure 10. Characteristics of (a) the PCM liquid-fraction profile and (b) the average PCM temperature profile during melting process for the cases of two, four, and six twisted fins.

To discuss the effects of increasing the number of installed twisted fins, the data for the heat storage capacity, total melting time, and heat storage rate at three different fin number 
cases are summarized in Table 3. The data show that faster heat storage with higher storage capacity and lower melting time can be best achieved when six fins are utilized. The rate of thermal energy stored in the PCM used was 31.74, 36.24, and 39.79 W, respectively. This means that there was almost $14 \%$ and $25 \%$ faster storage of heat due to the inclusion of six and four twisted fins, respectively, compared to using two fins. Therefore, under the condition of using the same PCM mass, increasing the number of installed twisted fins would help to produce a faster storage rate; the optimum storage rate was reached for the case of six twisted fins.

Table 3. The possible improvement in the heat storage capacity, melting time, and heat storage rate time for the cases of two, four, and six twisted fins.

\begin{tabular}{ccccc}
\hline Fins' Number & PCM Mass (kg) & $\begin{array}{c}\text { Thermal Storage } \\
\text { Capacity (J) }\end{array}$ & $\begin{array}{c}\text { Melting } \\
\text { Time (s) }\end{array}$ & $\begin{array}{c}\text { Heat Storage } \\
\text { Rate (W) }\end{array}$ \\
\hline Two & 0.3354 & $76,978.87$ & 2425 & 31.74 \\
\hline Four & 0.3354 & $76,938.91$ & 2123 & 36.24 \\
\hline Six & 0.3354 & $76,918.15$ & 1933 & 39.79 \\
\hline
\end{tabular}

\section{Conclusions}

A triple-tube heat storage system, equipped with twisted fins, was investigated during the melting process. The impact of the addition of twisted fins compared with the straight fins and no-fins cases, as well as the number of twisted fins inserted, were studied. In the system, the PCM was placed in the middle tube while hot water flowed through the inner and outer tubes in a counter-current direction as a superior method to store the thermal energy. The liquid fraction and temperature distributions of the PCM in the domain, as well as the melting time and heat storage rate, were assessed to find the best performance of the system. The results indicate higher advantages of adding twisted fins than using the straight fins or without fins implementation. The results show that adding four twisted fins reduced the melting time by $18 \%$ compared with using the same number of straight fins, and 25\% compared with the no-fins case when considering similar PCM mass.

Moreover, the melting time for the case of using four straight fins was $8.3 \%$ lower than that compared with the no-fins case. By growing the number of fins from two to four and six, the heat storage rate rose $14.2 \%$ and $25.4 \%$, respectively. This study presents a novel configuration for the fin's addition as an enhancement method in thermal energy storage applications.

Author Contributions: Conceptualization, M.G., and P.T.S.; methodology, M.G., and P.T.S.; software, A.S., J.M.M., A.H.E.; validation, P.T.S.; formal analysis, M.G., J.M.M., A.S., A.H.E., O.Y., P.T.S. and W.Y.; investigation, J.M.M., A.S., A.H.E., O.Y. and W.Y.; resources, O.Y. and W.Y.; writing-original draft preparation, M.G., J.M.M., A.S., A.H.E., O.Y., P.T.S. and W.Y.; writing-review and editing, M.G., J.M.M., A.S., A.H.E., O.Y., P.T.S. and W.Y.; visualization, A.S., A.H.E. and P.T.S.; supervision, M.G. and P.T.S.; All authors have read and agreed to the published version of the manuscript.

Funding: This research received no external funding.

Institutional Review Board Statement: Not applicable.

Informed Consent Statement: Not applicable.

Data Availability Statement: The data will be available on request.

Conflicts of Interest: The authors declare no conflict of interest.

\section{References}

1. Rahdar, M.H.; Emamzadeh, A.; Ataei, A. A comparative study on PCM and ice thermal energy storage tank for air-conditioning systems in office buildings. Appl. Therm. Eng. 2016, 96, 391-399. [CrossRef]

2. Ibrahim, N.I.; Khan, M.M.A.; Mahbubul, I.; Saidur, R.; Al-Sulaiman, F.A. Experimental testing of the performance of a solar absorption cooling system assisted with ice-storage for an office space. Energy Convers. Manag. 2017, 148, 1399-1408. [CrossRef] 
3. Hasnain, S. Review on sustainable thermal energy storage technologies, Part I: Heat storage materials and techniques. Energy Convers. Manag. 1998, 39, 1127-1138. [CrossRef]

4. Mahdi, J.M.; Lohrasbi, S.; Nsofor, E.C. Hybrid heat transfer enhancement for latent-heat thermal energy storage systems: A review. Int. J. Heat Mass Transf. 2019, 137, 630-649. [CrossRef]

5. Mahmood, A.S. Experimental Study on Double-Pass Solar Air Heater with and without using Phase Change Material. J. Eng. 2019, 25, 1-17. [CrossRef]

6. Mohammed, H.I.; Talebizadehsardari, P.; Mahdi, J.M.; Arshad, A.; Sciacovelli, A.; Giddings, D. Improved melting of latent heat storage via porous medium and uniform Joule heat generation. J. Energy Storage 2020, 31, 101747. [CrossRef]

7. Fan, L.; Khodadadi, J.M. Thermal conductivity enhancement of phase change materials for thermal energy storage: A review. Renew. Sustain. Energy Rev. 2011, 15, 24-46. [CrossRef]

8. Mahdi, J.M.; Nsofor, E.C. Solidification of a PCM with nanoparticles in triplex-tube thermal energy storage system. Appl. Therm. Eng. 2016, 108, 596-604. [CrossRef]

9. Mahdi, J.M.; Lohrasbi, S.; Ganji, D.D.; Nsofor, E.C. Simultaneous energy storage and recovery in the triplex-tube heat exchanger with PCM, copper fins and Al2O3 nanoparticles. Energy Convers. Manag. 2019, 180, 949-961. [CrossRef]

10. Mahdi, J.M.; Mohammed, H.I.; Hashim, E.T.; Talebizadehsardari, P.; Nsofor, E.C. Solidification enhancement with multiple PCMs, cascaded metal foam and nanoparticles in the shell-and-tube energy storage system. Appl. Energy 2020, 257, 113993. [CrossRef]

11. Sivasamy, P.; Devaraju, A.; Harikrishnan, S. Review on heat transfer enhancement of phase change materials (PCMs). Mater. Today Proc. 2018, 5, 14423-14431. [CrossRef]

12. Yang, L.; Huang, J.-N.; Zhou, F. Thermophysical properties and applications of nano-enhanced PCMs: An update review. Energy Convers. Manag. 2020, 214, 112876. [CrossRef]

13. Kamkari, B.; Shokouhmand, H. Experimental investigation of phase change material melting in rectangular enclosures with horizontal partial fins. Int. J. Heat Mass Transf. 2014, 78, 839-851. [CrossRef]

14. Yıldız, Ç.; Arıcı, M.; Nižetić, S.; Shahsavar, A. Numerical investigation of natural convection behavior of molten PCM in an enclosure having rectangular and tree-like branching fins. Energy 2020, 207, 118223. [CrossRef]

15. Tang, S.-Z.; Tian, H.-Q.; Zhou, J.-J.; Li, H. Evaluation and optimization of melting performance in a horizontal thermal energy storage unit with non-uniform fins. J. Energy Storage 2021, 33, 102124. [CrossRef]

16. Dai, R.; Mostaghimi, J.; Li, N.; Deng, T.; Wang, Q.; Zeng, M. Charging time and energy storage rate analysis of fin effect inside the horizontal tube for thermal energy storage. J. Clean. Prod. 2020, 273, 123030. [CrossRef]

17. Yang, X.; Guo, J.; Yang, B.; Cheng, H.; Wei, P.; He, Y.-L. Design of non-uniformly distributed annular fins for a shell-and-tube thermal energy storage unit. Appl. Energy 2020, 279, 115772. [CrossRef]

18. Nakhchi, M.; Esfahani, J. Improving the melting performance of PCM thermal energy storage with novel stepped fins. J. Energy Storage 2020, 30, 101424. [CrossRef]

19. Mahood, H.B.; Mahdi, M.S.; Monjezi, A.A.; Khadom, A.A.; Campbell, A.N. Numerical investigation on the effect of fin design on the melting of phase change material in a horizontal shell and tube thermal energy storage. J. Energy Storage 2020, $29,101331$. [CrossRef]

20. Dammak, K.; El Hami, A. Thermal reliability-based design optimization using Kriging model of PCM based pin fin heat sink. Int. J. Heat Mass Transf. 2021, 166, 120745. [CrossRef]

21. Xu, H.; Wang, N.; Zhang, C.; Qu, Z.; Cao, M. Optimization on the melting performance of triplex-layer PCMs in a horizontal finned shell and tube thermal energy storage unit. Appl. Therm. Eng. 2020, 176, 115409. [CrossRef]

22. Augspurger, M.; Choi, K.; Udaykumar, H. Optimizing fin design for a PCM-based thermal storage device using dynamic Kriging. Int. J. Heat Mass Transf. 2018, 121, 290-308. [CrossRef]

23. Zhang, C.; Sun, Q.; Chen, Y. Solidification behaviors and parametric optimization of finned shell-tube ice storage units. Int. J. Heat Mass Transf. 2020, 146, 118836. [CrossRef]

24. Kolioak, Y.; Radhakrishna, M.; Prasad, A. Optimization of Heat Energy Based on Phase Change Materials used in Solar Collector using Taguchi Method. Mater. Today Proc. 2020, 22, 2404-2411. [CrossRef]

25. Ren, H.; Lin, W.; Ma, Z.; Fan, W.; Wang, X. Thermal performance evaluation of an integrated photovoltaic thermal-phase change material system using Taguchi method. Energy Procedia 2017, 121, 118-125. [CrossRef]

26. Xie, J.; Yuan, C. Parametric study of ice thermal storage system with thin layer ring by Taguchi method. Appl. Therm. Eng. 2016, 98, 246-255. [CrossRef]

27. Lin, W.; Ma, Z. Using Taguchi-Fibonacci search method to optimize phase change materials enhanced buildings with integrated solar photovoltaic thermal collectors. Energy 2016, 106, 23-37. [CrossRef]

28. Lin, W.; Ma, Z.; Ren, H.; Gschwander, S.; Wang, S. Multi-objective optimisation of thermal energy storage using phase change materials for solar air systems. Renew. Energy 2019, 130, 1116-1129. [CrossRef]

29. Sun, X.; Mo, Y.; Li, J.; Chu, Y.; Liu, L.; Liao, S. Study on the energy charging process of a plate-type latent heat thermal energy storage unit and optimization using Taguchi method. Appl. Therm. Eng. 2020, 164, 114528. [CrossRef]

30. Li, Z.; Shahsavar, A.; Al-Rashed, A.A.A.A.; Talebizadehsardari, P. Effect of porous medium and nanoparticles presences in a counter-current triple-tube composite porous/nano-PCM system. Appl. Therm. Eng. 2020, 167, 114777. [CrossRef]

31. GmbH, R.T. RT35 Data Sheet. Available online: https://www.rubitherm.eu/en/index.php/productcategory/organische-pcm-rt (accessed on 10 November 2020). 
32. Talebizadeh Sardari, P.; Walker, G.S.; Gillott, M.; Grant, D.; Giddings, D. Numerical modelling of phase change material melting process embedded in porous media: Effect of heat storage size. Proc. Inst. Mech. Eng. Part A J. Power Energy 2019. [CrossRef]

33. Shahsavar, A.; Majidzadeh, A.H.; Mahani, R.B.; Talebizadehsardari, P. Entropy and Thermal performance Analysis of PCM Melting and Solidification Mechanisms in a Wavy Channel Triplex-Tube Heat Exchanger. Renew. Energy 2021, 165, 52-72. [CrossRef]

34. Mahdi, J.M.; Lohrasbi, S.; Ganji, D.D.; Nsofor, E.C. Accelerated melting of PCM in energy storage systems via novel configuration of fins in the triplex-tube heat exchanger. Int. J. Heat Mass Transf. 2018, 124, 663-676. [CrossRef]

35. Talebizadehsardari, P.; Mohammed, H.I.; Mahdi, J.M.; Gillott, M.; Walker, G.S.; Grant, D.; Giddings, D. Effect of airflow channel arrangement on the discharge of a composite metal foam-phase change material heat exchanger. Int. J. Energy Res. 2020. [CrossRef]

36. Al-Abidi, A.A.; Mat, S.; Sopian, K.; Sulaiman, M.Y.; Mohammad, A.T. Internal and external fin heat transfer enhancement technique for latent heat thermal energy storage in triplex tube heat exchangers. Appl. Therm. Eng. 2013, 53, 147-156. [CrossRef]

37. Xu, Y.; Ren, Q.; Zheng, Z.-J.; He, Y.-L. Evaluation and optimization of melting performance for a latent heat thermal energy storage unit partially filled with porous media. Appl. Energy 2017, 193, 84-95. [CrossRef]

38. Mat, S.; Al-Abidi, A.A.; Sopian, K.; Sulaiman, M.Y.; Mohammad, A.T. Enhance heat transfer for PCM melting in triplex tube with internal-external fins. Energy Convers. Manag. 2013, 74, 223-236. [CrossRef]

39. Mahdi, J.M.; Nsofor, E.C. Melting enhancement in triplex-tube latent thermal energy storage system using nanoparticles-fins combination. Int. J. Heat Mass Transf. 2017, 109, 417-427. [CrossRef]

40. Mahdi, J.M.; Nsofor, E.C. Solidification enhancement of PCM in a triplex-tube thermal energy storage system with nanoparticles and fins. Appl. Energy 2018, 211, 975-986. [CrossRef] 